\title{
Curative Management of Small HCCs: Time to Reconsider the Rules?
}

\author{
François Cauchy $\cdot$ Jacques Belghiti
}

Published online: 25 October 2014

(C) Société Internationale de Chirurgie 2014

Tumor size plays a significant part in the decision making of the management of HCC patients. For those with isolated lesions $<2 \mathrm{~cm}$, the expected rarity of microvascular invasion and satellite nodules has led to advocate both radiofrequency ablation and non-anatomical resection (NAR) as suitable curative treatments [1]. In the present issue of World Journal of Surgery, three articles, however, bring new insights regarding the underestimated oncologic risk of isolated small lesions which should lead to reconsider the curative management of these patients. First, the study of Zhong et al. [2] reports often underestimated rates of microvascular invasion and intrahepatic micrometastases of 16.2 and $13.4 \%$, respectively, in single HCCs $<2 \mathrm{~cm}$. In this setting, the observed $0 \%$ rate in lesions $<1.5 \mathrm{~cm}$ also highlights that the current $2 \mathrm{~cm}$ cutoff value is probably insufficient and represents a solid argument supporting removal of the tumor-bearing parenchyma along with its portal tributaries using anatomic resection (AR). In the same way, the study of Kazunari et al. [3] reports that as many as $15 \%$ of isolated $\mathrm{HCCs}<2 \mathrm{~cm}$ display features of poorly differentiated components. Even though tumor differentiation is well known to influence the oncologic prognosis, its assessment currently remains difficult in a preoperative setting and more refined tools are, therefore, required. In that sense, while the studies of Kazunari et al. [3] and of Thomasset et al. [4] emphasize the value of AFP and DCP in discriminating between low-risk and high-risk small HCCs, the reported different cutoff values also tend to support the need for a better grading of these markers. Obviously, it is only when this will be achieved that locoregional and resectional therapies will allow obtaining similar results as liver transplantation in patients without severe underlying parenchymal lesions.

\section{References}

1. Eguchi S, Kanematsu T, Arii S, Okazaki M, Okita K, Omata M, Ikai I, Kudo M, Kojiro M, Makuuchi M, Monden M, Matsuyama Y, Nakanuma Y, Takayasu K (2008) Liver Cancer Study Group of Japan. Comparison of the outcomes between an anatomical subsegmentectomy and a non-anatomical minor hepatectomy for single hepatocellular carcinomas based on a Japanese nationwide survey. Surgery. 143(4):469-475

2. Kazunari S, Masamichi M, Yu O, Yusuke K, Masafumi I, Masaji, Kenji I, Hiromitsu K, Goro W (2014) The influence of poor histological differentiation grade on the outcome of liver resection for hepatocellular carcinomas $2 \mathrm{~cm}$ or smaller in size. World $\mathrm{J}$ Surg. doi:10.1007/s00268-014-2806-6

3. Thomasset SC, Dennison AR, Garcea G (2014) Ablation for recurrent hepatocellular carcinoma: a systematic review of clinical efficacy and prognostic factors. World J Surg (in press)

4. Zhong Y, Deng M, Xu R (2014) Reappraisal of evidence of microscopic portal vein involvement by hepatocellular carcinoma cells with stratification of tumor size. World J Surg. doi:10.1007/ s00268-014-2807-5
F. Cauchy $(\bowtie) \cdot$ J. Belghiti

HPB Surgery and Liver Transplantation Unit, Beaujon Hospital, 100, Boulevard du General Leclerc, Clichy 92110, France e-mail: fafatoubib@gmail.com 